
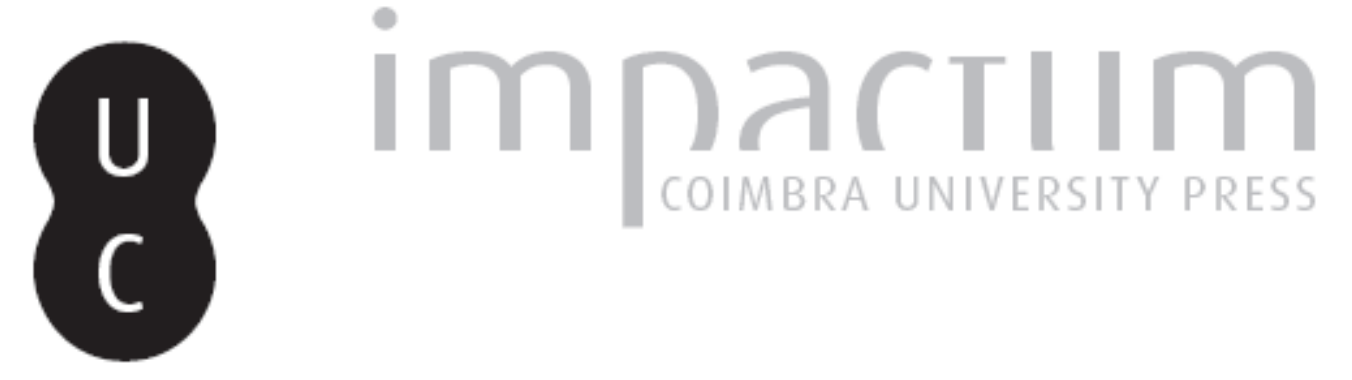

\title{
[Recensão a] Pedro e Inês - O futuro do passado - Congresso Internacional - Coordenação Científica de Maria Helena da Cruz Coelho
}

Autor(es): $\quad$ Santos, Maria José Azevedo

Publicado por: Centro de História da Sociedade e da Cultura

URL persistente:

URI:http://hdl.handle.net/10316.2/39402

DOI:

DOI:http://dx.doi.org/10.14195/1645-2259_13_20

Accessed : $\quad$ 26-Apr-2023 14:36:20

A navegação consulta e descarregamento dos títulos inseridos nas Bibliotecas Digitais UC Digitalis, UC Pombalina e UC Impactum, pressupõem a aceitação plena e sem reservas dos Termos e Condições de Uso destas Bibliotecas Digitais, disponíveis em https://digitalis.uc.pt/pt-pt/termos.

Conforme exposto nos referidos Termos e Condições de Uso, o descarregamento de títulos de acesso restrito requer uma licença válida de autorização devendo o utilizador aceder ao(s) documento(s) a partir de um endereço de IP da instituição detentora da supramencionada licença.

Ao utilizador é apenas permitido o descarregamento para uso pessoal, pelo que o emprego do(s) título(s) descarregado(s) para outro fim, designadamente comercial, carece de autorização do respetivo autor ou editor da obra.

Na medida em que todas as obras da UC Digitalis se encontram protegidas pelo Código do Direito de Autor e Direitos Conexos e demais legislação aplicável, toda a cópia, parcial ou total, deste documento, nos casos em que é legalmente admitida, deverá conter ou fazer-se acompanhar por este aviso. 

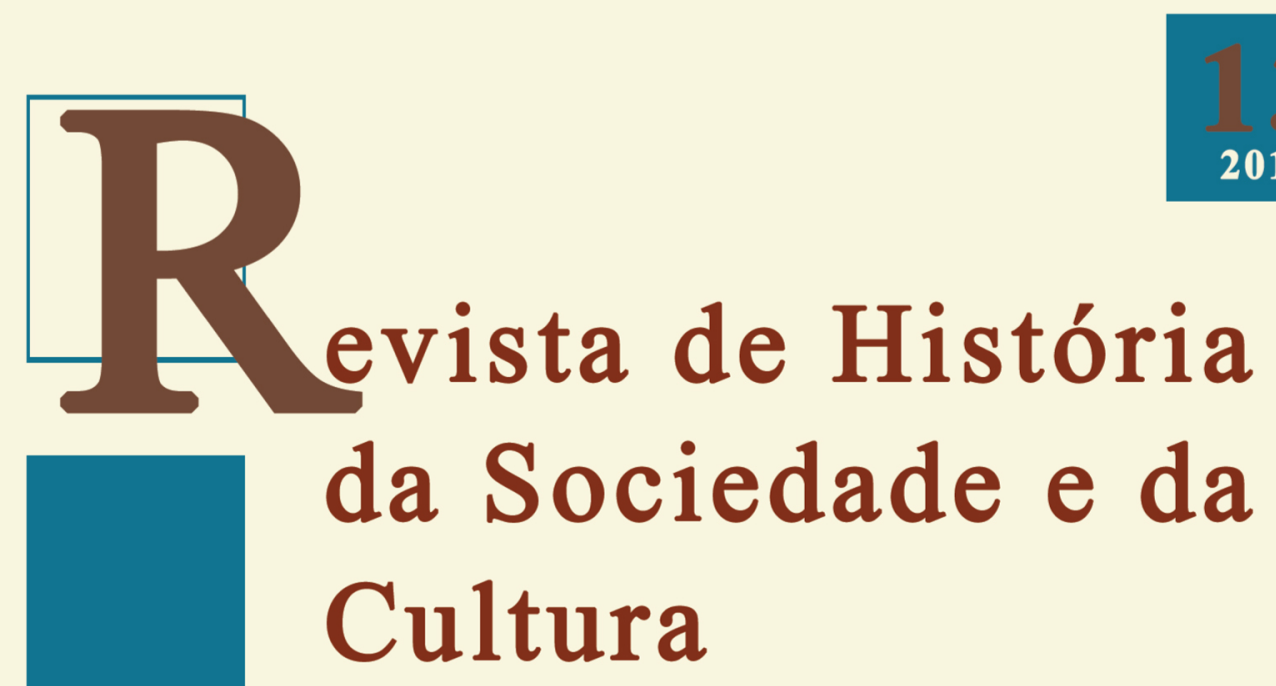

2013

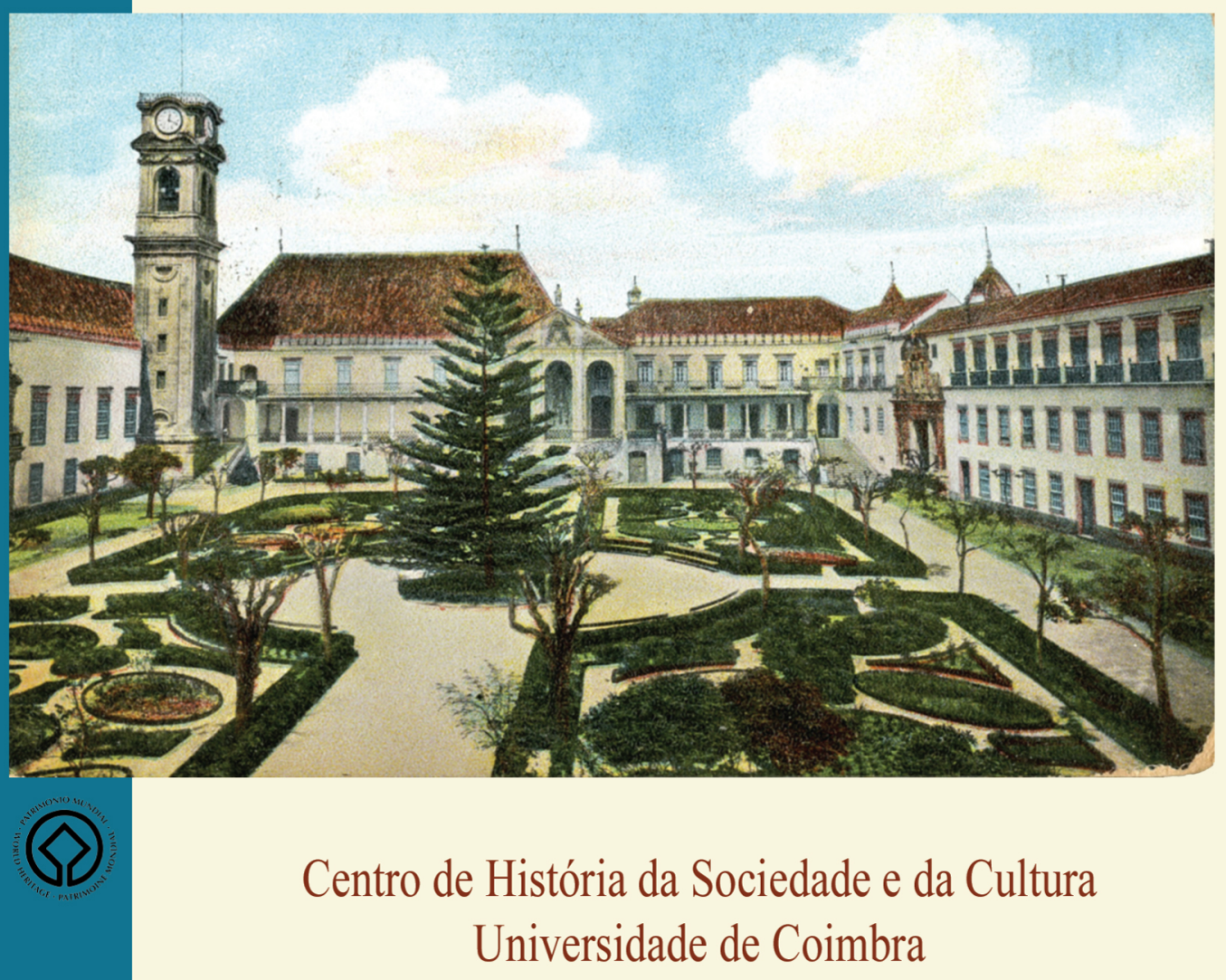

Coimbra 
simbólica pela escrita, levados a cabo por um grupo de historiadores oriundos da Europa Central, assumidamente adeptos da Nova História Cultural, que têm em Marco Mostert um dos seus maiores especialistas. Não se podendo tratar de uma lacuna de conhecimento, resta-nos presumir que se trata de uma opção do autor. Nesse sentido, parece-nos sair reforçada a ideia de que Pierre Chastang tenta demarcar-se de alguns trabalhos sobre práticas de escrita urbanas, abrindo uma perspectiva renovada de procurar relançar uma história social das cidades, em bases diferenciadas. Contudo, pensamos que em La ville, le gouvernement et l'écrit à Montpellier (XII ${ }^{e}-X I V^{e}$ siècles). Essai d'histoire sociale se evidencia apenas um primeiro fôlego dessa intenção, um ensaio, como o diz, sem ainda qualquer tipo de consolidação.

\section{Filipa Roldão}

filiparoldao@hotmail.com

Pedro e Inês - O futuro do passado - Congresso Internacional - Coordenação Científica de Maria Helena da Cruz Coelho, ed. Associação de Amigos de D. Pedro e D. Inês, Coimbra, 2013, 3 vols., 259+213+262 págs.

Com o Alto Patrocínio de Sua Excelência o Presidente da República Portuguesa, o Congresso em epígrafe realizou-se, entre os dias 28 e 31 de Março, de 2012, em Coimbra, em Montemor-o-Velho e, a encerrar, em Alcobaça. Um número significativo de instituições, culturais ou científicas, e autarquias, uniram-se para a comemoração dos 650 anos da trasladação de Inês de Castro do Convento de Santa Clara para o Mosteiro de Alcobaça. Sob a coordenação científica de Maria Helena da Cruz Coelho, acompanhada de perto por uma Comissão de que fizeram parte Bernardo Vasconcelos e Sousa, Jorge Pereira de Sampaio (também Programador-Geral das Comemorações), José Carlos Seabra Pereira e a signatária desta recensão, foi criteriosamente construído um Simpósio internacional cuja envergadura a edição em apreço retrata de forma consistente. Com efeito, foi possível reunir mais de quatro dezenas de estudiosos da temática, portugueses (o maior número), brasileiros e espanhóis, entre eles referências da Litera- 
tura, da Arte e da História inesianas. Do labor de quatro dias, em que só o entusiasmo, o convívio alegre e o esforço desempenhado pela Comissão Executiva conseguiram atenuar a fadiga própria das viagens e das jornadas longas de trabalho, resultou o tríptico bibliográfico que, em páginas, atinge a soma de mais de sete centenas. Os textos são da exclusiva responsabilidade dos autores, enquanto a edição ficou a cargo da Associação dos Amigos de D. Pedro e D. Inês criada, em 2005, aquando das comemorações dos 650 anos da morte de Inês de Castro, cuja característica está em congregar as principais autarquias pela história das quais passam, de uma forma ou de outra, os amores entre Pedro e Inês. Refiro-me, em particular, a Coimbra, a Montemor-o-Velho, a Alcobaça, à Lourinhã, entre outros. Como recenseadora, torna-se claro que nos é muito difícil fazer uma apreciação crítica à obra na sua globalidade quer intrínseca quer mesmo extrínseca.

Ainda assim pode perguntar o leitor: o que traz de novo uma tão espessa publicação?

Em primeiro lugar, a presença, lado a lado, de dezenas de autores, consagrados uns, promissores outros. A diversidade das abordagens e das disciplinas e ciências: da iconografia e iconologia à música, do teatro à poesia, das artes à literatura, da história à divulgação de fontes inéditas ou pouco conhecidas.

São disto exemplo, "A fonte dos Amores no Arquivo da Quinta das Lágrimas, 1364-1916”, de Maria da Assunção Alarcão Júdice; “O mito de Inês de Castro nas letras alemãs dos séculos XVII e XVIII”, de Maria Manuela Gouveia Delille"; "Arremedos paródicos ao episódio de Inês de Castro", de Manuel Ferro, entre tantos outros. Enfim, a revisitação de aspectos de temática inesiana para melhores reflexões, outras perspectivas, diferentes aproximações, múltiplas perguntas e dúvidas. Citem-se: "Por que foi morta Inês de Castro?", de Bernardo Vasconcelos e Sousa; "Inês de Castro: memórias, lendas e o mito", de Maria Leonor Machado de Sousa; "O túmulo de Inês de Castro: memória de uma Rainha", de Francisco Pato de Macedo; "Los reinos de Portugal y Castilla en tempos de Inés de Castro", de Ermelindo Portela Silva. Trata-se, na verdade, de um assunto interpelante, provocador, em tudo universal e perene.

Por último, uma menção especial merece o Requiem a Inês de Castro, do compositor Pedro Macedo Camacho, obra apresentada no âmbito do 
Congresso, em estreia mundial, pela Orquestra Clássica do Centro e pelo Coro, hoje designado Inês de Castro, no dia 28 de Março, na Sé Nova de Coimbra.

Por tudo o que fica dito, o Congresso em apreço e a prova escrita, agora editada, contribuem para enriquecer a historiografia inesiana ao mesmo tempo que lançam sementes para o cultivo de novas espécies histórico-científicas e culturais sobre Pedro e Inês.

\section{Maria José Azevedo Santos}

Universidade de Coimbra e Centro de História da Sociedade e da Cultura da Universidade de Coimbra mazevedo_santos@yahoo.com

\section{COElHo, Maria Helena da Cruz - O Município de Coimbra. Monumentos Fundacionais. Promoção e Direcção do Projecto: Maria José Azevedo Santos. Editores: Câmara Municipal de Coimbra e Imprensa da Universidade de Coimbra, Coimbra, 2013, 258 págs.}

Coimbra celebrou, em 2011, 900 anos do foral outorgado aos habitantes da cidade, pelo Conde D. Henrique e D. Teresa, no dia 26 de Maio de 1111. Disso dá testemunho verdadeiro um "pedaço" de bom pergaminho de coiro, original, em visigótica de transição para a carolina, do presbítero D. Telo, conservado no Arquivo Nacional da Torre do Tombo. Entretanto, o pelouro da cultura da Câmara Municipal tomou este aniversário como argumento feliz para conceber uma programação científico-cultural exigente, criativa e interdisciplinar. ${ }^{1}$

Com efeito, o vasto programa comemorativo incluía a publicação não só do foral de 1111 mas de todos os documentos responsáveis pela origem, evolução e consolidação do concelho de Coimbra até ao século XVI. Vice-Presidente, então, da Autarquia de Coimbra, promovi e dirigi este projecto ambicioso, com a assessoria de Joana Gouveia Loureiro,

1 Diga-se, a este propósito, que Coimbra recebeu o Prémio de Melhor Programação Cultural Autárquica 2011 atribuído ex aequo pela Sociedade Portuguesa de Autores em cerimónia solene, no Centro Cultural de Belém, no dia 28 de Fevereiro de 2012. 